\title{
Hypoglossal nerve stimulation for obstructive sleep apnea: updated position paper of the German Society of Oto-Rhino-Laryngology, Head and Neck Surgery
}

\author{
Armin Steffen ${ }^{1,2} \circledast$. Clemens Heiser ${ }^{3,8} \cdot$ Wolfgang Galetke $^{4,9} \cdot$ Simon-Dominik Herkenrath $^{4,10} \cdot$ Joachim T. Maurer ${ }^{2,11}$. \\ Eck Günther $^{3,12} \cdot$ Boris A. Stuck ${ }^{3,13} \cdot$ Holger Woehrle $^{5,6,14} \cdot$ Jan Löhler $^{7,15} \cdot$ Winfried Randerath ${ }^{4,10}$
}

Received: 14 May 2021 / Accepted: 20 May 2021 / Published online: 21 June 2021

(c) The Author(s) 2021

\begin{abstract}
Since the first statement of the German Society of Oto-Rhino-Laryngology, hypoglossal nerve stimulation (HNS) is meanwhile an established treatment option for obstructive sleep apnea (OSA). There are three HNS systems available in Germany which differ in their technical details of the underlying comparable basic principle. For the unilateral HNS with respiratory sensing, several comparative studies, high-volume register analysis and long-term reports exist. The continuous HNS without respiratory sensing does not require a sleep endoscopy for indication. For the bilateral continuous HNS as the single partially implantable device, a feasibility study exists. For indication, the assessment of positive airway pressure failure by sleep medicine is crucial, and the decision for HNS should be made in discussion of other treatment options for at least moderate OSA. The implantation center holds primarily responsibility among the interdisciplinary sleep team and is primary contact for the patient in problems. This depicts why structural processes are required to secure outcome quality and minimize the complications. The aftercare of HNS patients can be provided interdisciplinary and by different medical institutions, whereat, minimal reporting standards to document outcome and usage are recommended.
\end{abstract}

Keywords Hypoglossal nerve stimulation · Obstructive sleep apnea $\cdot$ Neurostimulation $\cdot$ CPAP failure $\cdot$ Sleep endoscopy DISE

Armin Steffen

armin.steffen@uksh.de

1 Department for Otorhinolaryngology, University of Lübeck, Ratzeburger Allee 120, 23538 Lübeck, Germany

2 Sleep Medicine Work Group of the German Society of Oto-Rhino-Laryngology, Head and Neck Surgery (DGHNO), Bonn, Germany

3 Work Group Sleep Surgery of the German Society for Sleep Research and Medicine (DGSM), Schwalmstadt-Treysa, Germany

4 Work Group Apnea of the German Society for Sleep Research and Medicine (DGSM) (DGSM), Schwalmstadt-Treysa, Germany

5 Section 8 Sleep Medicine of the German Respiratory Society (DGP), Berlin, Germany

6 German Professional Association of Pulmonologists, (BdP), Heidenheim, Germany

7 German Professional Association of Ear, Nose, Throat-Physicians (BVHNO), Neumünster, Germany
8 Department for Otorhinolaryngology, Technical University Munich, Munich, Germany

9 Department for Pulmonolgy, VAMED Klinik Hagen-Ambrock, Hagen, Germany

10 Institute of Pneumology at the University of Cologne, Bethanien Hospital, Clinic for Pneumology and Allergology, Centre of Sleep Medicine and Respiratory Care, Solingen, Germany

11 Department of Otorhinolaryngology, Head and Neck Surgery, Sleep Disorders Center, University Hospital Mannheim, Mannheim, Germany

12 Practice for Otorrhinolaryngology, Stuttgart, Germany

13 Department of Otolaryngology/Head \& Neck Surgery, University Hospital Giessen and Marburg, Philipps-Universität Marburg, Marburg, Germany

14 Sleep and Ventilation Center Blaubeuren, Lung Center Ulm, Ulm, Germany

15 ENT Clinic, Maienbeeck, Bad Bramstedt, Germany 


\section{Introduction}

Since the first position paper of the sleep medicine work group of the German Society of Oto-Rhino-Laryngology, Head and Neck Surgery (DGHNO) [1], hypoglossal nerve stimulation (HNS) attained increasing attention in the treatment of obstructive sleep apnea (OSA). Within recent years, there is accumulating evidence on patient selection, surgical techniques, treatment pathways, long-term data as well as experiences with special patient groups. With this positional paper, the implementation of HNS in treatment pathways of the German healthcare systems shall be highlighted. The position paper was established and finally approved by several sleep medicine related societies on November 27 th 2020: The sleep medicine work group of the DGHNO, the work group apnea and sleep surgery of the German society for sleep research and medicine, the German Professional Association of pulmonologists, the German Professional Association of Ear, Nose, and Throat-physicians, and the German Respiratory Society [2].

\section{Aims}

This positional paper aims to

a. Warrant a high quality of interdisciplinary patient care regardless of residence in Germany and socio-economic status,

b. Provide a structural, procedural, and outcome-based interdisciplinary care pathway in the provision of hypoglossal nerve stimulation,

c. Implement evidence-based decision making,

d. Minimize therapy risks and adverse effects,

e. Avoid OSA-associated complications and co-morbidities as well as to improve quality of life among patients with non-adherence to positive airway pressure therapy (PAP).

\section{Available hypoglossal nerve stimulation systems}

Currently, there are three hypoglossal nerve stimulation systems for OSA treatment available in Germany. For a more detailed description of the underlying technology, there are extensive descriptions and reviews [3, 4]. The Federal Joint Committee (G-BA) decided in their assessment from March 5th 2020 that "neither the underlying principle (2.4.1.2) nor the indication (2.4.1.3) differ relevantly between the assessed treatment method with regard to the established inpatient treatment method; thereby, the here assessed treatment method (here, the system provided by Nyxoah, Inc.--added information by the authors) reveals no novel theoretical-academic concept" [5].

\section{Selective hypoglossal nerve stimulation with respiratory sensing (Inspire Medical Systems, Inc.)}

Selective hypoglossal nerve stimulation with respiratory sensing uses an intercostal sensor for the detection of the patient's breathing cycle. This information is processed in the subclavian impulse generator, which then delivers an impulse to the stimulation electrode at the lateral neck. The submentally positioned cuff of the electrode activates protrusor branches of the distal hypoglossal nerve and herewith, opens the upper airway. The system received CE marking in October 2010, FDA approval in April 2014, and accreditation by the Japanese health authority PMDA in June 2018.

In an early study [6], a complete concentric collapse (CCC) at velum level during drug-induced sleep endoscopy (DISE) was associated with a highly increased non-response rate to treatment with HNS. With a prevalence of 20-25\% among PAP intolerant patients [7, 8], such CCC is frequent and needs to be ruled out in a DISE. There was a good response rate to HNS in a study with randomized therapy withdrawal [8] for patients with a body mass index (BMI) below $32 \mathrm{~kg} / \mathrm{m}^{2}$ and an apnea hypopnea index between 20 and 50 events per hour. Data from national and international, multicenter and single-center cohort and register studies revealed that inclusion criteria could be broadened (AHI between 15 and 65/h, BMI up to $35 \mathrm{~kg} / \mathrm{m}^{2}$ ) without risking lower response rates and lower therapy adherence [9-12]. In a comparison of response rates, patients with a BMI below $32 \mathrm{~kg} / \mathrm{m}^{2}$ did not differ from patients with a BMI between 32 and $35 \mathrm{~kg} / \mathrm{m}^{2}$ [13]. In publications of the international ADHERE register, the rate of unwanted events and complications is about $2-6 \%$ [10].

For optimal positioning of the stimulation electrode, neuromonitoring guidance is recommended to identify the protrusor branches of the hypoglossal nerve [14-16]. The system is activated four weeks after implantation with another four weeks to allow acclimatization. About eight weeks after implantation, a polysomnographic therapy adjustment is performed in a sleep laboratory to optimize OSA therapy. Later, a regular annual follow-up appointment is recommended, including objective therapy control with a home-sleep testing device (HST). If needed, the polysomnographic adjustment is repeated. The impulse generator contains a lithium battery with an approximated lifetime of about 10 years. 


\section{Continuous hypoglossal nerve stimulation (LivaNova, Inc., former ImThera Medical)}

Continuous hypoglossal nerve stimulation does not require respiratory sensing. Six electrodes are located in a ring-like stimulation cuff around the main hypoglossal nerve and alternately stimulate the targeted nerve branches by changing electric fields. The impulse generator is located in the subclavian area and contains an accumulator, which needs to be charged regularly. The lifespan of the rechargeable battery is estimated to last about 15 years. Four-six weeks after implantation, the most suitable electrode combination and amplitude to achieve a stabilization of the upper airway are calculated in a polysomnographic-assisted study. In contrast to selective HNS with respiratory sensing, a DISE is not necessary for the indication $[17,18]$. The aura6000 system received CE marking in March 2012. Since 2015, the FDA approval study ("THN3") is still running, but is no longer actively recruiting participants.

\section{Bilateral continuous hypoglossal nerve stimulation (Nyxoah S.A.)}

In contrast to both systems described before, the Genio system (Nyxoah S.A.) is a submentally placed HNS with wing-like electrodes close to both hypoglossal nerves [19]. The distal placements allow an activation of more protrusor branches and opens the airway by tongue protrusion similar to selective HNS. The preset processing unit with a rechargeable battery transcutaneously delivers the required energy to the implant during sleep. The stimulation is phasic and asynchronous and is adjusted in a polysomnography similar the continuous HNS. The external processing center and accumulator is charged during daytime. A DISE is necessary to rule out a complete concentric collapse at velum level. The Genio system received CE marking in March 2019. The FDA approval study ("DREAM") started in September 2020.

\section{Overview of evidence}

As all available systems differ in technical details, mode of operations, and market approval, the review of evidence has to be differentiated.

For the HNS with respiratory sensing, about 100 publications exist and cover a long-term view up to 60 months. For market approval, the STAR study evaluated the safety and effectiveness of the HNS in Europe and the US during 2010 and 2013. This study covering a selected cohort of 126 patients with moderate to severe OSA has the highest evidence level, as it contains a randomized therapy withdrawal arm of therapy responders. Data on annual follow-up reports exist up to 5 years [8, 20-22]. Currently, a randomized controlled study with therapy withdrawal of 89 patients regardless of treatment responsiveness is under review ("EFFECT"). This study assessed the recurrence of daytime sleepiness and OSA events under subtherapeutic voltage [23]. There are several multicenter cohort studies which confirmed safety and effectiveness of daily routine use [9, 24-26], including 2- and 3-years of follow-up data [25]. In addition, the outcomes of monocentric 4-year follow-up results can also be found in the literature [26]. In therapy responders, HNS with respiratory sensing can normalize sleep-related quality of life with very good patient satisfaction [27, 28]. Patient age and previous upper airway surgery appear not to affect effectiveness $[29,30]$. Several retrospective comparative studies show better OSA outcomes of HNS treatment compared to traditional sleep surgery [31-33]. First reports documented positive effects on glucose metabolism and heart frequency variability [34, 35]. A recent prospective multicenter study, which show relevant improvement of OSA in HNS therapy compared with no treatment [12].

For the continuous HNS ImThera system, there are first studies for safety and effectiveness which reveal an improvement in OSA [17, 36]. In the next months, the results of the European and US randomized controlled study with 135 patients are expected to be published ("THN3").

So far, Nyxoah's Genio system was assessed in two smaller case series during device development. There is a publication on 27 patients with a 6-month follow-up published in 2019, which demonstrated the benefit of this system [19].

\section{Indication}

a. Assessment of PAP-nonadherence

Careful candidate selection is essential for good HNS outcomes. Currently, HNS is recommended as a second line treatment after PAP therapy. Therefore, besides suitable evaluation regarding any HNS, the reasons for PAP failure need to be documented during the screening process [37]. It is, therefore, advisable to check for PAP optimization options and to evaluate other OSA treatment options in the individual decision-making process.

b. Interdisciplinary decision-making is based on implanting center's authority/responsibility

The interdisciplinary patient care pathways with HNS are usually collaboratively lead by the departments of otorhinolaryngology and sleep medicine. A standardized treatment pathway and a good communication between specialties are 
Table 1 Structural requirements in performing the treatment

Surgical team, experienced in head neck surgery and a 24-h on-call duty

Sleep medicine team, experienced in patient care with obstructive sleep apnea

Proficient experience in endoscopic evaluation of the upper airway, especially of nasopharynx, velopharynx, oropharynx including tonsils, tongue base, hypopharynx, and epiglottis

Knowledge in the assessment and interpretation of sleep diagnostics, opportunity to perform home sleep tests or polysomnography, where applicable, in multidisciplinary cooperation

Knowledge in performing drug-induced sleep endoscopy, in particular on the evaluation of HNS suitability

Performing the surgical implantation using optical magnification and intraoperative neuromonitoring after training and certification by the manufacturer

Opportunity to provide adequate postoperative care in patients with moderate to severe obstructive sleep apnea, low-threshold access to intermediate care units and/or intensive care units

Activation and titration of patients together with qualified technical assistants

Provide resources for long-term follow-up of HNS and if necessary, in corporation with external sleep medicine physician

Experience in transnasal endoscopy for postoperative HNS therapy optimization

Timely availability for HNS patients with requests

Implanting center managed preferably by otorhinolaryngologists or head neck surgeons with sleep medicine qualification/board certification

HNS hypoglossal nerve stimulation

essential to achieve good OSA control and effective usage of HNS. Therefore, several requirements should be fulfilled by the HNS team (Table 1, see chapter 6 ). Ideally, patient selection, DISE, implantation, therapy adjustment and control are carried out in a department of otorhinolaryngology with profound sleep medicine knowledge or in a sleep medicine center under surveillance of the implanting surgeon. The HNS therapy can be provided by teams across different locations, as long as the responsibilities and communication have been clarified and regular team conferences on patient pathways take place. It has to be highlighted that the implanting center plays a central role in the responsibility for patient selection and therapy adjustment and should be capable of evaluating sleep medicine reports and assessing the documentation of PAP nonadherence.

The DISE is relevant for whether a patient is suitable for PAP alternatives, especially regarding HNS with respiratory sensing $[6,7]$. During this investigation, the exclusion criteria of complete concentric collapse at velum level and other treatment options can be assessed or ruled out [37]. Therefore, profound expertise is needed to perform and evaluate a DISE. There is respective literature about DISE technique and requirements [38, 39].

In case of external referrals, standards are necessary for preoperative diagnostics and their ongoing quality conformance. Therapy adjustment should only be performed outside the implanting center with great care, to ensure that the recommended and correct treatment pathway is followed. In particular, in case of suspected technical issues, the implanting centers are mainly responsible for the therapy and should be addressed immediately. Therapy outcomes should be assessed in joint conferences with all partners.
Informed consent for the implantation needs certified forms and should be completed by a specialist of the implanting center.

c. Guidelines of the German society for sleep research and medicine

Recently in 2020, the guidelines for the treatment of sleep-related breathing have been updated under guidance of the German society for sleep research and medicine, DGSM. Using a structured literature review, this S3-leveled guideline recommends-with its primary focus on HNS with respiratory sensing - that HNS should be considered in patients with moderate to severe OSA (AHI between 15 and 65 events per hour), PAP intolerance or inefficiency, in the absence of Class II or higher obesity (BMI below $35 \mathrm{~kg} /$ $\mathrm{m}^{2}$ ), and in patients without anatomical obstructions in the upper airway (evidence level 1b, recommendation level B, concordant strong consensus) [40].

\section{d. Clinical practice}

In Germany, there are more than 35 implanting centers for HNS with specialized infrastructure and certification by the manufacturer. HNS is considered in patients using the following criteria:

Apnea hypopnea index between 15 and 65 events per hour,

Body mass index $\leq 35 \mathrm{~kg} / \mathrm{m}^{2}$,

The portion of central events is $\leq 25 \%$ in relation to the entire night's AHI, 
Table 2 Recommended variables regarding patient's aspects, therapy effects and usage

\begin{tabular}{lllll}
\hline Variable & Baseline & Implantation & $\begin{array}{l}\text { Early follow- } \\
\text { up }\end{array}$ & $\begin{array}{l}\text { Annual } \\
\text { follow- } \\
\text { up }\end{array}$ \\
\hline $\begin{array}{l}\text { Demographic aspects } \\
\text { (age, gender, height, weight) }\end{array}$ & $\mathrm{X}$ & & $\mathrm{X}$ & $\mathrm{X}$ \\
Apnea hypopnea index (AHI) & $\mathrm{X}$ & $\mathrm{X}$ & $\mathrm{X}$ \\
Oxygen desaturation-index (ODI 4\%) & $\mathrm{X}$ & & $\mathrm{X}$ & $\mathrm{X}$ \\
Epworth Sleepiness Scale (ESS) & $\mathrm{X}$ & $\mathrm{X}$ & $\mathrm{X}$ \\
Side effects and complications & & $\mathrm{X}$ & $\mathrm{X}$ \\
Therapy adherence (usage per night) & & & $\mathrm{X}$ & $\mathrm{X}$ \\
\hline
\end{tabular}

The exclusion of a complete concentric collapse at the velum level during DISE When bilateral HNS or HNS with respiratory sensing is considered,

PAP-nonadherence or non-compliance (chapter 4),

The absence of neuromuscular diseases and

Appropriate motivation of the patient.]

\section{Quality requirements in a hypoglossal nerve stimulation center}

Hypoglossal nerve stimulation therapy should be allocated in centers with sleep medicine expertise and specialized infrastructure. The treatment pathway and responsibilities should be defined when the center is established and need regular review.

\section{a. Structural requirements for the treatment}

The following structural requirements need to be fulfilled in implanting centers. This assures a smoother process, better outcome quality and helps to minimize complications (Table 1).

b. Follow-up of patients with hypoglossal nerve stimulation

It is very important to provide long-term follow-up resources for patients with HNS. The patient care and follow-up can be carried out in the implanting center or by external physicians with sleep medicine qualification. The implanting centers need to provide timely availability for potential medical and technical complications. Special consultation hours help to provide appropriate service for HNS candidates and patients. If the follow-up is provided by external sleep physicians, the implanting center should be updated about the patients' treatment course for quality management (see chapter 6).

\section{Quality management and supply research}

For assurance of therapy quality, implanting centers should document therapy effects properly and do regular evaluations (Table 2). Industry driven registries and independent assessments are valuable and should cover data security concerns. As minimal requirements, patient aspects, therapy effects and usage should be recorded too.

In recent years, OSA treatment with HNS is welldescribed as a second line therapy in PAP failure and positioned in national guidelines. All three available HNS systems differ in technical details of the common underlying therapy principle, indication and, most of all, evidence. The implanting centers obtains the main responsibility within the interdisciplinary treatment concept. Quality management is essential for the entire treatment pathway, especially for the long-term follow-up.

Funding Open Access funding enabled and organized by Projekt DEAL.

Open Access This article is licensed under a Creative Commons Attribution 4.0 International License, which permits use, sharing, adaptation, distribution and reproduction in any medium or format, as long as you give appropriate credit to the original author(s) and the source, provide a link to the Creative Commons licence, and indicate if changes were made. The images or other third party material in this article are included in the article's Creative Commons licence, unless indicated otherwise in a credit line to the material. If material is not included in the article's Creative Commons licence and your intended use is not permitted by statutory regulation or exceeds the permitted use, you will need to obtain permission directly from the copyright holder. To view a copy of this licence, visit http://creativecommons.org/licenses/by/4.0/.

\section{References}

1. Steffen A, Heiser C, Herzog M, Bergler W, Rothmeier N, Maurer JT (2015) Stellungnahme der Taskforce „Neurostimulation bei Schlafapnoe“ zur Stimulation der oberen Atemwege.” LaryngoRhino-Otol 94:221-224

2. Steffen A et al (2021) Die Stimulation des Nervus hypoglossus in der Behandlung der obstruktiven Schlafapnoe-Aktualisiertes Positionspapier der Arbeitsgemeinschaft Schlafmedizin der 
DGHNO-KHC. Laryngo-Rhino-Otol 100:15-20. https://doi.org/ 10.1055/a-1327-1343

3. Teschler H, Werther S, Bassenge-Sauer Z, Weinreich G, Stuck BA (2016) Elektrische Atemwegsstimulation zur Therapie der obstruktiven Schlafapnoe. Pneumologe 13:376-387

4. Heiser C, Hofauer B (2017) Hypoglossusnervstimulation bei CPAP-Versagen-evolution einer Alternativbehandlung für Patienten mit obstruktiver Schlafapnoe. HNO 65:99-106

5. https://www.g-ba.de/downloads/40-268-6402/2020-03-05_137h_ BAh-19-002_HGNS-OSA_TrG.pdf, letzter Zugriff am 18 Oct 2020

6. Vanderveken OM et al (2013) Evaluation of drug-induced sleep endoscopy as a patient selection tool for implanted upper airway stimulation for obstructive sleep apnea. J Clin Sleep Med 9:433-438

7. Hasselbacher K, Bruchhage KL, Abrams N, Steffen A (2018) Schlafendoskopie und komplett konzentrischer Weichgaumenkollaps bei CPAP-Nutzungsproblemen. HNO 66:837-842

8. Strollo PJ et al (2014) Upper-airway stimulation for obstructive sleep apnea. N Engl J Med 370:139-149

9. Steffen A, Sommer JU, Hofauer B, Maurer JT, Hasselbacher K, Heiser C (2018) Outcome after one year of upper airway stimulation for obstructive sleep apnea in a multicenter German postmarket study. Laryngoscope 128:509-515

10. Heiser $\mathrm{C}$ et al (2019) Post-approval upper airway stimulation predictors of treatment effectiveness in the ADHERE registry. Eur Respir J 53:1801405

11. Heiser C, Knopf A, Bas M, Gahleitner C, Hofauer B (2017) Selective upper airway stimulation for obstructive sleep apnea: a single center clinical experience. Eur Arch Oto-Rhino-Laryngol 274:1727-1734

12. Mehra R et al (2020) Upper airway stimulation versus untreated comparators in positive airway pressure. Ann Am Thorac Soc J12:1610-1619

13. Huntley C, Steffen A, Doghramji K, Hofauer B, Heiser C, Boon M (2018) Upper airway stimulation in patients with obstructive sleep apnea and an elevated body mass index: a multi-institutional review: impact of BMI on upper airway stimulation. Laryngoscope 128:2425-2428

14. Heiser C, Hofauer B, Lozier L, Woodson BT, Stark T (2016) Nerve monitoring-guided selective hypoglossal nerve stimulation in obstructive sleep apnea patients. Laryngoscope 126:2852-2858

15. Maurer JT et al (2012) Operative technique of upper airway stimulation: an implantable treatment of obstructive sleep apnea. Oper Tech Otolaryngol Head Neck Surg 2012:227-233

16. Heiser C, Thaler E, Soose RJ, Woodson BT, Boon M (2018) Technical tips during implantation of selective upper airway stimulation. Laryngoscope 128:756-762

17. Friedman M et al (2016) Targeted hypoglossal nerve stimulation for the treatment of obstructive sleep apnea: six-month results. Laryngoscope 126:2618-2623

18. Maurer JT, Nascimento S, Ferreira Gomes E (2019) Ist die medikamenteninduzierte Schlafendoskopie ein Prädiktor für den Therapieerfolg der atmungsunabhängigen, kontinuierlichen Hypoglossus-Stimulation bei obstruktiver Schlafapnoe? Somnologie 23:S10-11

19. Eastwood PR et al (2020) Bilateral hypoglossal nerve stimulation for treatment of adult obstructive sleep Apnea. Eur Respir J 55:1901320

20. Woodson BT et al (2016) Three-year outcomes of cranial nerve stimulation for obstructive sleep apnea: the STAR trial. Otolaryngol Head Neck Surg 154:181-188

21. Woodson BT et al (2014) Randomized controlled withdrawal study of upper airway stimulation on OSA: short- and long-term effect. Otolaryngol Head Neck Surg 151:880-887
22. Gillespie MB et al (2017) Upper airway stimulation for obstructive sleep apnea: patient-reported outcomes after 48 months of follow-up. Otolaryngol Head Neck Surg 156:765-771

23. Heiser et al. Effect of upper airway stimulation in patients with obstructive sleep apnea (EFFECT): a randomized controlled crossover trial. (Under review)

24. Huntley C, Kaffenberger T, Doghramji K, Soose R, Boon M (2017) Upper airway stimulation for treatment of obstructive sleep apnea: an evaluation and comparison of outcomes at two academic centers. J Clin Sleep Med 13:1075-1079

25. Steffen A, Sommer UJ, Maurer JT, Abrams N, Hofauer B, Heiser C (2020) Long-term follow-up of the German post-market study for upper airway stimulation for obstructive sleep apnea. Sleep Breath 24:979-984

26. Zhu Z, Hofauer B, Wirth M, Heiser C (2020) Long-term changes of stimulation intensities in hypoglossal nerve stimulation. J Clin Sleep Med 16:1775-1780

27. Hasselbacher K, Hofauer B, Maurer JT, Heiser C, Steffen A, Sommer JU (2018) Patient-reported outcome: results of the multicenter German post-market study. Eur Arch Oto-Rhino-Laryngol 275:1913-1919

28. Hofauer B, Steffen A, Knopf A, Hasselbacher K, Heiser C (2019) Patient experience with upper airway stimulation in the treatment of obstructive sleep apnea. Sleep Breath 23:235-241

29. Zhu Z, Hofauer B, Wirth M, Hasselbacher K, Frohnhofen H, Heiser C, Steffen A (2018) Selective upper airway stimulation in older patients. Respir Med 140:77-81

30. Huntley C, Vasconcellos A, Doghramji K, Hofauer B, Heiser C, Boon M (2018) Upper airway stimulation in patients who have undergone unsuccessful prior palate surgery: an initial evaluation. Otolaryngol Head Neck Surg 159:938-940

31. Huntley C, Topf MC, Christopher V, Doghramji K, Curry J, Boon M (2019) Comparing upper airway stimulation to transoral robotic base of tongue resection for treatment of obstructive sleep Apnea. Laryngoscope 129:1010-1013

32. Huntley C, Chou DW, Doghramji K, Boon M (2018) Comparing upper airway stimulation to expansion sphincter pharyngoplasty: a single university experience. Ann Otol Rhinol Laryngol 127:379-383

33. Yu JL, Mahmoud A, Thaler ER (2019) Transoral robotic surgery versus upper airway stimulation in select obstructive sleep apnea patients: TORS versus UAS in select OSA patients. Laryngoscope 129:256-258

34. Steffen A et al (2018) Upper airway stimulation in obstructive sleep apnea improves glucose metabolism and reduces hedonic drive for food. J Sleep Res 28:e12794

35. Dedhia RC et al (2019) Hypoglossal nerve stimulation and heart rate variability: analysis of STAR trial responders. Otolaryngol Head Neck Surg 160:165-171

36. Mwenge GB, Rombaux P, Dury M, Lengele B, Rodenstein D (2013) Targeted hypoglossal neurostimulation for obstructive sleep apnoea: a 1-year pilot study. Eur Respir J 41:360-367

37. Fietze I et al (2020) Wenn CPAP nicht genutzt oder nicht vertragen wird-Vorschlag für eine standardisierte Terminologie. Somnologie 24:102-105

38. De Vito A et al (2014) European position paper on drug-induced sedation endoscopy (DISE). Sleep Breath 18:453-465

39. De Vito A et al (2018) European position paper on drug-induced sleep endoscopy: 2017 Update. Clin Otolaryngol 43:1541-1552

40. Stuck BA et al (2020) Teilaktualisierung S3-Leitlinie Schlafbezogene Atmungsstörungen bei Erwachsenen. Somnologie 24:176-208

Publisher's Note Springer Nature remains neutral with regard to jurisdictional claims in published maps and institutional affiliations. 